\title{
Video games and the soulless business culture
}

\author{
Tam-Tri Le \\ Centre for Interdisciplinary Social Research \\ Phenikaa University, Hanoi, Vietnam \\ Written in Ho Chi Minh city, on 3 August 2021
}

On the Internet, there is a type of joke about "losing hope in humanity" over something trivial (to the general population). But sometimes, such incidents may expose huge systemic problems behind them. In this short writing, I will talk about my personal opinions on something specific: my favorite video games and the explicit shame within the industry.

Like many other kids growing up in the late 90s and the 2000s, I love Blizzard's franchises (Warcraft, Starcraft, Diablo). I spent countless hours not only playing but also daydreaming about their rich universes and stories during my high school and even college years; and I am still watching Starcraft 2 tournaments these days. The company (back when they were still a rather small team and not yet integrated into Activision) was known for their high-quality crafts (pun intended), honor, and community-friendly attitude. But not anymore, the good people have left, and the soul has withered.

In fact, the company has started to become a living meme (or worse - a demonized figure) in the global entertainment industry many years ago. The company has embodied the very tragic stories they masterfully wrote for their early games. Notably, Warcraft III Reforge has one of the lowest user-rating ever on Metacritic, and the causes can be summed up as solely pursuing short-term profit [1].

Recently, Bloomberg also reported a series of incidents involving lawsuits and other human rights violation within the company, especially the mistreatment of their female employees [2]. Most sadly, the protesting employees expressed that unless there was considerable financial damage, the higher-ups would not really care to listen.

In a dramatic fashion, it can be said that I have grown up to see my childhood hero slowly turned into the monstrous thing they once swore to destroy. And not just Activision-Blizzard, the video-gamer community has seen the same transitioning pattern in other developers and publishers too. For example, the giant corporate Electronic Arts is an infamous meme source in a bad way, known for their frequent legal problems surrounding "loot-box" and (probably) gambling risk-inducing tactics [3].

If the development process from ethical small companies into unethical giant corporates prevailed, then money would ultimately become the only thing they worship, over either products or humans. Even worse, the selfish pattern is still going strong even in a global pandemic, where we humans are supposed to unite and care for each other. If the business culture cannot even appreciate the human factors in such a direct relationship, then it would certainly be difficult for the system to function sustainably in terms of harmony with the natural environment - something requires an even more "long-term vision" [4]. 


\section{References}

1. Schreier, J. (2021a, July 22). Blizzard Botched Warcraft III Remake After Internal Fights, Pressure Over Costs. Bloomberg. https://www.bloomberg.com/news/articles/2021-07-22/insideactivision-blizzard-s-botched-warcraft-iii-reforged-game

2. Schreier, J. (2021b, July 30). Activision Blizzard Workers Walked Out. Did the Company Hear Them? Bloomberg.Com. https://www.bloomberg.com/news/newsletters/2021-07-30/activisionblizzard-workers-walked-out-did-the-company-hear-them

3. Johnson, E., \& Ivany, K. (2021, April 26). Video game giant EA steering players into loot-box option in popular soccer game, insider says. CBC. https://www.cbc.ca/news/gopublic/fifa21loot-boxes-electronic-arts-1.5996912

4. Vuong, Q.-H. (2021). The semiconducting principle of monetary and environmental values exchange. Economics and Business Letters, 10(3), 284-290. https://reunido.uniovi.es/index.php/EBL/article/view/15872 